\title{
Taking Late Ming Dynasty Printmaking as an Example to Analyze the Influence of Consumption on the Development Direction of Art
}

\author{
Jie Xiao \\ Southeast University, NangJing210000, Jiangsu, China
}

\begin{abstract}
From the end of the 15th century to the beginning of the 16th century, great changes have taken place in the history of the world, called the "Great Navigation era", which has gradually opened the prelude to "globalization". China in the late Ming Dynasty was just in this division point, from economy to thought, all blooming in the elegance of an empire, and the book publishing industry in Ming Dynasty developed rapidly and brightly with the blessing of the Ming Taizu's "imperial edict except book tax". Book illustration is inspired by the original function of reading picture interpretation and on essential means of participating in market competition. Illustration books are very popular, almost to the point that there is no book without intention. At the same time, the illustration transitioned from narrative to decorative. This change relates to the fact that the illustration has changed from narrative to decorative. It is because of the change in their demand that the citizen class has become the key customer group to have a great relationship, which has led to a change in art illustration in the late Ming Dynasty.
\end{abstract}

Keywords: Book Illustration; Narrative; Decorative; Consumption Demand; Art Development Direction

\section{The development of book publishing in the late Ming Dynasty}

The Southern Song scholar Zheng Qiao talked about the role of book illustrations in the "General History Tupu Brief": "Pictures, classics; books, latitudes. One latitude and one latitude, the difference becomes a text... If you see a book, you don't see the picture, and you don't hear it. Shape; see the picture without seeing the book, and the person who sees it does not hear the words. The picture, the appointment; the book, the master. That is to say, the book is for easy, that is, the book is for difficulty. Ancient scholars have needs for learning. On the left, the book is placed on the right; the picture is in the picture, and the reason is in the book. So people are easy to learn, and learning is easy to work" ${ }^{[1]}$. Books and illustrations are evolving together. Only words without pictures are like listening to sound without seeing its shape; while pictures without words become just seeing its form and not hearing its sound. Therefore, books and illustrations complement each other, without one being imperfect.

Anne E Mclaren "constructing new reading public in xlate Ming China" said: In the mid-sixteenth century, authors and publishers of vernacular texts realized, probably for the first time in the history of Chinese print culture, that their reading public was no longer limited to the learned classes. Prefaces and commentaries of the era show an emerging awareness, which broadened and strengthened during the seventeenth century, that the potential readership for this text was a heterogeneous one of officials, literati, collectors among the new class of nouveaux riches, members of the laity, common people, the relatively uneducated,, and even the all-inclusive "people of the empire" or "people of the four classes "This gradual, mass-oriented acceptance group has prompted book publishers to adjust their publishing content in order to appeal to the public. The book's content published in the late Ming Dynasty was of unprecedented richness.

A large number and variety were printed by the Ming Dynasty. The printed matter was mainly divided into three types: banknotes (on a trial basis during the Hongwu period) and sales vouchers for state-protected commodities, such as salt and tea. According to the "Nanjing Household Ministry Records": "Forgery tea leads were executed. I have no property in the house. The informant will reward twenty taels of silver"[2]; the second is the annual calendar. Printing of the annual calendar is a national privilege, printed by local officials and distributed to families. Local governments also print other forms, such as yellow books, to record the household registration status of various places; thirdly, the development of books, both official and private printing, has promoted the formation of a pattern of book publishing.

In 1599, Yu Xiangdou, a bookseller in Jianyang, Fujian Province, edited and published "Universal Authenticity". The first chapter was "Astronomical Auspicious Differences "The source of these "auspicious differences" was not mentioned by Yu Xiangdou, but it should come from folklore. Since ancient times, people believed that "auspiciousness" was a kind of signal from 
the heavens. This understanding of the signals from the heavens came mainly from official institutions. As the son of heaven, the emperor inherited the destiny of heaven, so only the emperor had the right to divination foresee the will of heaven. Yu Xiangdou's book may bring disasters to him, but it can further prove that the publishing industry caters to consumer needs: if there is a large readership who wants to know how to divinationthe subsequent almanac or divination books would cater to that demand. Late Ming book publishing. Products produced by industries that target the mass market as a typical Fujian area include: illuminated reading materials, moral education textbooks, compilation of legal provisions, novels, dramas, pornographic reading materials, humorous tales, guidebooks, introductions to foreign customs, and various Knowledge excerpts and cheap rewritings of all kinds of books will be published as long as there are readers and sales.

\section{The development of book illustrations in the late Ming Dynasty}

In order to attract readers, publishers rushed to print popular readings and practical guides, and engaged in vigorous selfpromotion. Illustrations became fashionable. Books such as novels, scripts, encyclopedias should be accompanied by at least one or two woodcut prints to suit the late Ming Dynasty. Value the sense of pleasure of reading. This style of printmaking has been developed in two ways to attract readers' eyes, one is refinement; the other is popularization. Refinement refers to a more detailed description of the prints, not only a description of the evolution of the story, but also, more importantly, a depiction of the details. A certain segment of the story development is regarded as a separate painting work, and it is gradually separated from the article in the later stage. The story develops into a decorative painting; popularization means that books are more complex and curious in content, in order to respond to a more popular audience, and they are simpler in vernacular expressions in text, and in order to match the content of the book, printmaking is more complicated than popularity.

The production process of printmaking is divided into three procedures: drawing drafts, knife-engraving and engraving, and transfer from the plate. Since the Chinese engraving tradition usually does not deliberately pursue the expressiveness of the knife method, it often has the characteristics of line drawing, particularly, the line drawing style. At the same time, printmaking is closely related to the craftsmanship tradition. The decorativeness of craftsmanship has a great influence on it. For example, in theatrical prints, illustrations are not only narrative but also decorative. On the other hand, prints Mass production has become an intermediary for the dissemination of the artwork. The same composition appears in a variety of artifacts. The prints and crafts interact and influence each other, resulting in both narrative and decorative illustrations of prints.

Narrative and decorative are originally two different development directions. Those with narrative should have a single specific event as the subject of the picture, guiding readers to think about the content of the story development; decorative is based on the redundancy or repetition of redundant information. The characteristic, which directly appeals to the vision, attracts the reader's gaze to linger on the screen without paying attention to expressing of a specific meaning or content, and does not have the developmental nature of the time dimension.

The economic development of the Ming Dynasty, the world has a high enthusiasm for learning, but for ordinary people there are still obstacles to pure text reading, so pictures have become the most direct and effective means of dissemination of information, such as the ten-year edition of Chongzhen. "The record of papermaking in ", although the text is described in about 800 words, but it is accompanied by "cutting the bamboo and floating pond", "boiling the full water", "dangling the material into the curtain", "covering the curtain and pressing the paper" and "drying and drying". Five illustrations illustrate the papermaking process in the most clear, concise, and continuous manner. The birth of book illustrations is an explanation of the text. As a drama text, "West Chamber" runs through the Ming and Qing Dynasties, with many editions and various illustration styles. The popular "West Chamber" in the Ming and Qing Dynasties generally has five books with 21 folds, each with 40 folds, plus a wedge, and each fold has a name, sometimes four characters, sometimes two characters.

The book illustrations of the late Ming Dynasty began with narrative. At first, they were aided by words and gradually became popular. Later, with the participation of English-speaking people in publishing, a number of illustrations evolved towards the "elegant" aspect, highlighting the artistic quality.

When popular novels in the late Ming Dynasty became a desk reading material that could be widely carried and read, the visual dimension became relatively more prominent. The content of the book not only contained text, but also the appearance of pictures and corresponding critical text which provide guidance on reading. Illustrations influence readers' patterns or habits of reading text. At the same time, in some book publications, the commentary text occupies a page and borders. These borders (branches) correspond to the content of the illustrations, coexisting decorative and narrative.

\section{The influence of consumption on the direction of art development}

In the production process of art, art works are only products of a conceptual form, which must be embraced by the audience before they can become real products, complete the entire art production activities, and realize various functions of art. Artwork can become a reality product only if there is an audience. As this art event comes to an end, all sorts of consumers and consumption behaviors also have an impact on the development of art.

The illustrations of the books published in the Ming Dynasty can be divided into narrative and decorative. In the late Ming Dynasty, the narrative of book illustrations weakened and the decorativeness increased. Some of the illustrations occupy two or four folds, and they are no longer only dominated by characters, but later appear as flowers and birds. The style of the main or decorative pattern is independent of the form to imply the development of the story, such as the original version of the Zhouyue school in Jinling Wanjuanlou in the 19th year of the Wanli period in the Ming Dynasty (1591) "New Journal Correction of Ancient Chinese Characters Interpretation of the Three Kingdoms Popular Romance", Qiantang King Shenxiu during the Wanli period The original block-printed version of "San Suiping Demon Biography", etc., uses double-sided continuous large illustrations to form two consecutive pages into one picture. The illustrations have left the main text and became independent painting art. This led to 
the fact that the illustrations presented such a situation and the participation of the fine English speakers at that time was greater. Relationship.

Whether actively participating or passively copying, the fine English people have become the creators of book illustrations, but it is undeniable that ordinary engravers are still the subject of creation. They use fine English people's paintings as a model, reprocessed and created, and gradually formed a fixed template, such as the late Ming Dynasty. The moonlight illustration composition that appeared in the Chongzhen period was developed by the engraver on the basis of the modification of the literati paintings, and then gradually replaced the large image composition of the full-page spread in the Wanli period and became a new popular method.

The elite English-speaking people in the upper strata of society have also began to change their concept of light business. Jingling School Zhong Xing said: "The breeding of goods is not a small path, and the choice is based on power. When choosing people, management and business talents, Huang and Lao learn. "Almost in"[3]; Li Mengyang also said: "The husband, the businessman and the scholar are in the same heart with different skills, so the good merchants, who are good at dealing with wealth and cultivating wise deeds, are therefore productive but not harmful.' Judging from the assessment of the emerging civic class by the English-speaking people, the civic class and the literati are no longer two conflicting classes but communicate and develop together. In the late Ming Dynasty, Chen Jiru recorded: "Xi Yixian Hao Elderly Tour"[4], Hui merchant Wu Longtian said: "Although I have traveled in Jia, I have seen home Scholars of the scribes only hate not holding the whip"[5] Literati and businessmen are friends, or they write inscriptions, biographies, or for them Children teach or draw to publish novels and operas.

Craig Clunas "Superfluous Things: Material Culture and social Status in Early Modern China" mentioned: "When the special consumption activities originally exclusive to scholars were imitated by merchants and even civilians, they faced extreme social competition. Great pressure and anxiety occur spontaneously. In reality, what merchants and civilians imitate is their positive expression of the needs of cultural consumption, while what scholars are worried about is the downward shift in culture, so scholars hope to continue to make distinctions and distinctionsAnd any new distinction is often replaced by a new round of imitation, so the so-called elite culture is constantly being copied and moved down, and popular culture is constantly enriched and active."[6]."Longwuzhi" is an art appreciation guide book by Ming Wen Zhenheng, which records the aesthetics of fine English people in the late Ming Dynasty. Mode, this book is also widely circulated among ordinary citizens. Corrige pointed out that businessmen and common people continue to imitate, which stimulated the continuous improvement of the aesthetics of the civilian class to a certain extent. Traditional narrative illustrations can no longer satisfy demand.

In the end, book illustrations developed to the late Ming Dynasty and a decorative sidebar appeared. The patterns of these sidebars were mostly related to the story of the article, and in the illustrations appeared poems created by splicing to comment on the evolution of the story. These more obscure pictures and texts Readers are required to have a deep knowledge base, whereas businessmen or ordinary citizens are unable to draw and refine. Literati needs to participate, the status of merchants change, and English-speaking people participate in the production. After the drawing is completed, the ordinary citizens are inevitably arty, but It is because they hope to obtain the same social status and discourse power as the English-speaking people, so they beg to improve the aesthetics and art under the leadership of the English-speaking people, and increase their pursuit of art. This phenomenon has prompted the businessmen to publish books and illustrations from narrative to decorative Sexual transformation.

As the key makers and participants of social and cultural development, the English speakers have always regulated the mainstream direction of cultural development. The citizen class was born and expanded, and wanted to gain cultural power like them, so they began to imitate and mimic the English speakers. Inviting them to participate in the development of new cultures has contributed to the development of late Ming art in a new direction, not only the traditional elite culture, but also the mass culture of the citizen class with the involvement of elite English speakers.

\section{Conclusion}

German book artist Hans Peter Werburg in "The Art of Books in Development": "Every book is a thing, an objective object, which can be held in the hand, it is not just the outer shell of the content. The appearance of a book will be influenced by its content. The appearance of this book is an integral part of its content. The two rely on each other and cannot be separated, just like the lyrics of a singing play or a song cannot be linked to each other. Separate the same." ${ }^{[7]}$ Books in the late Ming Dynasty were the art of combining book content with illustrations. Auxiliary, succinct description of the text, to the emphasis on the quality of illustrations and artistic pictures, illustrations have gradually become a more obscure way of commenting, based on a shift in readership.

At the same time, there was also a unique attitude towards material culture in the late Ming Dynasty. One of the central thesis of Colige's Longwuzhi: It was in the 16th century (mainly the latter half) that the traditional elite felt that its social status was affected. Threats, turning to "inventing taste" as a means to emphasize what matters is not only the possession of aesthetic luxury goods, but also the manner in which they are possessed. As a special period in the late Ming Dynasty, material and culture developed at a high level. Under the conditions of abundance, I hope to gain the right to speak of the traditional English speakers in culture, so that ordinary citizens imitate the literati, imitating their way of life. For example, Li Jialing made meticulous details of the funeral goods from the tomb of the merchant Wangzhen. The research shows that these paintings buried in 1494 clearly indicate that individual members of the early Ming Dynasty merchant class were already enjoying the decorations of the "literati" lifestyle. The imitation of the English-speaking people by ordinary citizens has to a certain extent, triggered the counter-attack of the English-speaking people. They have turned to the pursuit of "interest" in art, searching for art in ordinary things instead of being limited to traditional paintings and calligraphy. This change It is like a circular circle: the civic class pursues artistry in order to gain the voice of the literati class, and the literati class seeks the artistry in ordinary culture in order to avoid the imitation of the civic class. Together, they determine the direction of art development in the late Ming Dynasty. 


\section{References}

1 Song. Zheng Qiao. Tongzhi. Siku Quanshu (374) [M]. Shanghai Ancient Books Publishing Company, 1989.

2 Nanjing Household Department Records (1550). Vol. 12.39 [M].

3 Craig Clunas. Superfluous Things: Material Culture and social Status in Early Modern China [M]. SDX Joint Publishing Company, 2015.

4 (Ming) Zhong Xing. Yinxiuxuan Collection. Volume 5. Cheng Ci Gong Xinglue [M]. Shanghai Ancient Books Publishing Company, 1992.

5 (Ming) Li Mengyang. Kong Tongji. Volume 44. Ming Dynasty Wang Wenxian's epitaph. [M]. National Library Press, 2014. 6 (Ming) Yuan Zhongdao. Ke Xuezhai Collection. Wu Longtian Chuan. Beiye [M]. Shanfang Publishing Company, 1936.

7 (Germany) Vilburg. The developing book art [M]. People's Fine Arts Publishing Company, 1997. 